\title{
Comparative Studies of Adsorption of Heavy Metals from Cement Waste Water Using Activated Carbon from Palm Kernel Husk, Coconut and Groundnut Shells
}

\author{
${ }^{* 1}$ ODISU, T ; ${ }^{2}$ EDOMWONYI-OTU, LC; ${ }^{1}$ ANIH, EC \\ ${ }^{1}$ Department of Chemical Engineering, Federal University of Petroleum Resources, Effurun, Nigeria \\ ${ }^{2}$ Department of Chemical and Petroleum Engineering, Delta State University, Oleh, Nigeria \\ *Corresponding Author Email: teddyodi2002@yahoo.com
}

\begin{abstract}
Cement waste water is a major source of heavy metal pollution which requires removal before disposal. This paper therefore evaluates the comparative adsorption of heavy metals from cement waste water using activated carbon from palm kernel husk, coconut and groundnut shells in line with standard methods. With $0.1 \mathrm{M} \mathrm{KOH}$ as activating agent at $400{ }^{\circ} \mathrm{C}$, PKH and GNS reduced zinc concentration in water from $0.06 \mathrm{mg} / \mathrm{l}$ to $0.01 \mathrm{mg} / \mathrm{l}$ while CCS reduced iron concentration by $50 \%$ for temperature range of $450{ }^{\circ} \mathrm{C}-500{ }^{\circ} \mathrm{C}$. However, when $0.1 \mathrm{M} \mathrm{ZnCl}$ was used as activating agent, all three adsorbents reduced the concentration of $\mathrm{Zn}, \mathrm{Fe}$ and $\mathrm{Pb}$ to $0.01 \mathrm{mg} / 1$ within the temperature range of $400{ }^{\circ} \mathrm{C}-450$ ${ }^{\circ} \mathrm{C}$ while Nickel was substantially reduced to $0.01 \mathrm{mg} / \mathrm{l}$ by all three adsorbents with $0.2 \mathrm{M} \mathrm{ZnCl}$ as activating agent for temperature range of $400{ }^{\circ} \mathrm{C}$ to $500{ }^{\circ} \mathrm{C}$. The result shows that all three materials could serve as adsorbents but their performance depends on temperature and activating agents. For palm kernel husk and coconut shell, their performance was inversely proportional to temperature, while groundnut shell shows a direct relationship. On the overall, the three precursors showed capacity as good adsorbent for treatment of cement waste- water.
\end{abstract}

DOI: https://dx.doi.org/10.4314/jasem.v23i5.30

Copyright: Copyright $($ C 2019 Odisu et al. This is an open access article distributed under the Creative Commons Attribution License (CCL), which permits unrestricted use, distribution, and reproduction in any medium, provided the original work is properly cited.

Dates: Received: 13 April 2019; Revised: 19 May 2019; Accepted 21 May 2019

Keywords: Cement, waste- water, activated- carbon, heavy-metals adsorption

The place of cement in the satisfaction of man's quest for structural and other forms of modern development is enormous (European cement association, 1996). However, cement production comes with serious environmental challenges like those arising from the waste water which is laden with heavy metals and other complex mixtures of chemicals which can trigger consequential changes in critical water qualities (Francis et al., 2014). In the consideration of water contaminants, heavy metals take the front row because they are especially dangerous, highly persistence and toxic (Gonzalo et al., 2010). They are hazardous to the biotic environment with adverse impact on vegetation, human, animal health and the eco system (Pandey et al., 2014; Radia et al., 2018). Also, excessive concentrations of heavy metals in the environment may harm human health, and its usage may leave dust deposits in eyes, ears and nasal passages, and may cause injury to the skin or mucous membranes. They also lower reproductive success, prevent proper growth and development and even cause death (Nur et al., 2014). They are nonbiodegradable and could distort enzyme function by attracting and forming bond with sulphur. However, due to the associated high cost of conventional treatment operations, cement producing companies now adapt some alternative measures in the management of their waste water. For example, in 2007, Dangote cement plant Gboko, had to re-inject more than $80 \%$ of its waste water into petroleum reservoirs (Wan et al., 2008) while about $18 \%$ was disposed into the environment. However, recycling of untreated waste water have the capacity to cause further problems like clogging of reservoir pores and making it difficult to continue to use such reservoir as water dumps. In a bid to avert the seeming high cost in conventional water treatment that may negatively affect cost of product and thus affect the Company's chances of remaining in business, the Oinyi River (situated in the Confluence town in Kogi and linked to river Niger and River Benue) which hitherto had served the people of North Central Nigeria for both domestic and industrial purposes is now being constantly perturbed by waste water from a cement industry. The degree of impact of this waste- water on the water quality is presently unknown as there is no documented information (Francis et al., 2014). However, there are reports of several disease outbreaks, unusual deaths and poor agricultural output around the area in recent times and other serious environmental damage as a result of improper treatment of waste water released to the environment 
from the cement industries in the state (Nwankwo et al., 2014). Conventional cement waste-water treatment has involved the application of unit operations or unit processes such as chemical precipitation, coagulation, adsorption, ion exchange and membrane filtration (Gregg and Singh, 2002; Mohan and Singh, 2002) Furthermore, among the aforementioned treatment technologies, adsorption has been reported as an efficient and economic option because of convenience and ease of operations and simplicity of design (Chengwen et al., 2014).

Although a number of adsorbent materials have been studied for their adsorptive abilities with some relatively promising success for the elimination of heavy metals from wastewater using various agricultural waste such as sugarcane bagasse, rice husk, oil palm shell, coconut shell, coconut husk etc (Lim and Aris, 2014 ; Nasim et al., 2004). The objective of this research is to study and compare the adsorptive capacities of activated carbon from coconut shell, groundnut shell and palm kernel husk for the removal of $\mathrm{Zn}, \mathrm{Fe}, \mathrm{Pb}, \mathrm{Cr}$ and $\mathrm{Ni}$ from cement waste water.

\section{MATERIALS AND METHODS}

The adsorbates solution of $\mathrm{Zn}, \mathrm{Fe}, \mathrm{Pb}, \mathrm{Cr}$ and $\mathrm{Ni}$ metal ions were prepared from analytical grade $\mathrm{FeSO}_{4} .7 \mathrm{H}_{2} \mathrm{O}, \mathrm{Pb}\left(\mathrm{NO}_{3}\right)_{2}, \mathrm{Cr}\left(\mathrm{NO}_{3}\right)_{3}$ and $\mathrm{NiCl}_{2} .6 \mathrm{H}_{2} \mathrm{O}$ following the method of Agbozu and Emoruwa, (2014). The precursors, coconut shells, palm kernel husks and groundnut shells (CCS, PKH and GNS respectively) obtained from Effurun market, in Delta State were washed using tap water to remove dirt and sands. The washed sample materials were sun dried for five (5) days and then pelletized into fine particles with the aid of a manual grinder and sieved to $120 \mathrm{~mm}$ mesh size - a physical treatment method. Similar method was reported by Agbozu and Emoruwa, (2014) in their experiment on batch adsorption of heavy metals $(\mathrm{Cu}$, $\mathrm{Pb}, \mathrm{Fe}, \mathrm{Cr}$, and $\mathrm{Cd}$ ) from aqueous solutions using coconut husk.

The furnace (DAIHAN-brand $®$ programmable Tube Furnace) was set at a temperature of $500{ }^{\circ} \mathrm{C}$. Then each of the sample materials placed in a crucible, was transferred to the muffle furnace (DAIHAN-brand® 1,200 ${ }^{\circ} \mathrm{C}$ Digital Muffle Furnace) for 2 hours to be carbonized. Carbonization increases the percentage of carbon in the adsorbents due to the loss of moisture content and volatile compounds. This is in line with Nur et al., (2014).

After two (2) hours of heating, the carbonized samples were each divided into four (4) parts in crucibles labeled A to D and allowed to cool. Samples in crucibles A to D were subsequently activated(chemical treatment) in the ratio of 2:3 (mass of sample: mass of activating agent) using $0.1 \mathrm{M}$ $\mathrm{KOH}, 0.2 \mathrm{M} \mathrm{KOH}, 0.1 \mathrm{M} \mathrm{ZnCl}_{2}$, and $0.2 \mathrm{M} \mathrm{ZnCl}_{2}$ respectively at $400{ }^{\circ} \mathrm{C}, 450{ }^{\circ} \mathrm{C}$ and $500{ }^{\circ} \mathrm{C}$ for three hours. All chemicals used were of analytical grades. The samples were then brought out of the muffle furnace and cooled in desiccators, after which they were washed several times with distilled water using a funnel and filter paper until a $\mathrm{pH}$ (measured using a Scout pro, ohaus, London $\mathrm{pH}$ meter) range between 5 and 6 was obtained. The adsorbent was then dried in an oven (Carbolite Gero High Temperature Laboratory Oven - LHT) at $170{ }^{\circ} \mathrm{C}$ for a period of 2 hours. Similar procedure was used by Bernard et al., (2013) in their studies on heavy metals removal from industrial wastewater by activated carbon prepared from coconut shells.

Batch adsorption of zinc, iron, chromium, lead and nickel from cement waste water was carried out to determine the adsorption capacity of activated carbon produced from the different plant materials, activated as highlighted above under the specified temperatures. The activated carbon $(10 \mathrm{mg}$, measured using Scout pro, Ohaus, London weighing balance) was added to $120 \mathrm{ml}$ of the waste water, agitated and allowed to contact for $180 \mathrm{mins}$ since the optimum contact time for PKH, GNS and CCS was $120 \mathrm{mins}$ to $240 \mathrm{mins}$ from studies by Elijah et al., 2009, William et al., 2016 and Chengwen et al., (2014). The mixture was then filtered using a filter paper into a $250 \mathrm{ml}$ beaker (Pyrex, England). The filtrate was analyzed to ascertain the concentration of heavy metals left using the Atomic Absorption Spectrophotometer (AAS) (Claisse LeNeo Fluxer). The control sample was untreated (UTD) cement wastewater with no adsorbent applied. After equilibrium was attained, the metal uptake capacity for each sample was calculated using values obtained from a mass balance measurement of the metal ion and applying the equation 1 in line with Eruola and Ogunyemi, (2014).

$q_{e}=\left(C_{o}-C_{e}\right) \times \frac{V}{m}$ 1

Where $m$ the mass of adsorbent $(\mathrm{g})$ is, $V$ is the volume of the solution (1), $C_{o}$ is the initial concentration of metal (mg/l), $C_{e}$ is the equilibrium metal concentration (mg/l) and $q_{e}$ is the metal quantity adsorbed at equilibrium $(\mathrm{mg} / \mathrm{g})$.

The percent removal of metal ions from the solution was calculated using equation 2 .

$\%$ removal $=\frac{\left(C_{o}-C_{e}\right)}{C_{o}} \times 100$ 
Hence, the amount of un-adsorbed metal ion $(\mathrm{mg} / \mathrm{l})=$ 1 - \% removal of metal ions from their solutions.

\section{RESULTS AND DISCUSSION}

Figures 1 to 2 show the results of the adsorbents ( $\mathrm{PKH}$, CCS, and GNS) activated with $0.1 \mathrm{M} \mathrm{KOH}$ for the adsorption of Zinc, Iron, Chromium, Lead and Nickel from the cement waste water as well as the control sample. Figure 1(a) specifically compared the performance of the three adsorbents produced at different activation temperatures on the removal of Zinc from the waste water. It was observed that at 400 ${ }^{\circ} \mathrm{C}$, PKH and GNS performed well giving $0.01 \mathrm{mg} / \mathrm{l}$ each of un-adsorbed Zinc while $0.03 \mathrm{mg} / \mathrm{l}$ was recorded for CCS. However, as the activation temperature increased from $400{ }^{\circ} \mathrm{C}$ to $450{ }^{\circ} \mathrm{C}$ and then $500{ }^{\circ} \mathrm{C}$, the performance of $\mathrm{PKH}$ and GNS was observed to decrease giving concentrations of unadsorbed Zinc of $0.04 \mathrm{mg} / 1,0.05 \mathrm{mg} / \mathrm{l}$ and $0.03 \mathrm{mg} / \mathrm{l}$, $0.04 \mathrm{mg} / \mathrm{l}$ respectively which indicates that the adsorption process is exothermic as commonly observed for organic adsorbents. It also suggests that the process may be physically driven (physical adsorption) and thus the resultant intermolecular forces between adsorbate and adsorbent are much weaker than those between adsorbate and solvent (Vinod et al., 2017). For CCS, it showed improvement in performance for higher temperatures (as above) giving the concentrations of un-adsorbed Zinc metal of $0.02 \mathrm{mg} / \mathrm{l}$ and $0.01 \mathrm{mg} / \mathrm{l}$. This is suggests a chemisorption process since increase in temperature results in increase in chemical reaction where increased temperature chemically changes the adsorbent and its adsorption sites/surfaces, capacity and activity. Also, the favorable intermolecular forces between adsorbate and adsorbent seem much stronger than those between adsorbate and solvent. This shows that the performance of the adsorbents for the removal of Zinc metal is a function of the activation temperature. Similar result was obtained by Al-Degs et al., (2007), for adsorption capacity of activated carbon for reactive dyes.

Figure 1(b) describes the removal of Iron at the different temperatures using the three adsorbents. PKH showed a consistent performance at all temperatures implying that temperature may not really affect its performance in the removal of Iron as the process seems likely to be more of a physical adsorption where the resultant intermolecular forces between adsorbate and adsorbent maintained a much weaker status compared to those between adsorbate and solvent irrespective of temperature. CCS gave a sharp improvement in performance as the amount of un-adsorbed Iron metal reduced by $50 \%$ on increased temperature from $400{ }^{\circ} \mathrm{C}$ to $500{ }^{\circ} \mathrm{C}$. This suggests a case of chemisorption as increase in temperature seems to positively affect the reaction rate. A report by Abdulrasaq and Basiru, (2010) showed a similar trend of $94 \% \pm 1.4 \%$ removal efficiency of $\mathrm{Fe}$ (III) ions from mono-component simulated waste effluent using coconut husk. GNS seems to be inconsistent in behavior for iron removal as temperature increased from $400{ }^{\circ} \mathrm{C}$ to $500{ }^{\circ} \mathrm{C}$. This suggests that application of GNS in iron removal is sensitive to temperature and seems to require specific activation temperature for optimum performance.

Figure 1(c) shows the removal of Chromium using the adsorbents within the temperature range. $\mathrm{PKH}$ and GNS show exothermic character suggesting a physical adsorption processes while for CCS, it was observed that optimum performance is clearly selective of temperature as activation sites are likely to become more and readily available at specific temperatures (Omar, 2011; Radia et al., 2018). The exceptional performance observed at $450{ }^{\circ} \mathrm{C}$ is indicative of the process temperature preference as there was no marked difference in the performance at $400{ }^{\circ} \mathrm{C}$ and $500{ }^{\circ} \mathrm{C}$.

Figure 2(a) highlights the removal of Lead under same conditions as above. The trend observed seems to be consistent for all three adsorbents as increasing temperature increased the performance of the adsorbents in Lead removal. As highlighted in discussing Figure 1, increasing temperature enhances reaction rate which suggests a chemical adsorption process. While all three adsorbents performance for the first time in this study maintained a consistent profile, the performance rating seems to favor GNS followed by CCS and PKH.

For the $0.1 \mathrm{M} \mathrm{KOH}$ treated adsorbents, Figure 2(b) highlights the removal of Nickel. It was observed that the removal of Nickel using PKH reduced but there was an observable increase with GNS as temperature increased suggesting physical and chemical processes respectively while CCS showed a consistent performance irrespective of change in temperature. This behavior could be due to (1) the surface area modification activity of the activating agent not in being in favor of the adsorption capability of the adsorbents at higher temperatures (2) the possibility of intermolecular interaction between the adsorbate (Nickel ions) and the surface of the adsorbent not supporting nickel adsorption and (3) the possibility of the resultant pore sizes of adsorbent occasioned by increasing activation temperature and activating agent not being able to freely accommodate the size of Nickel 

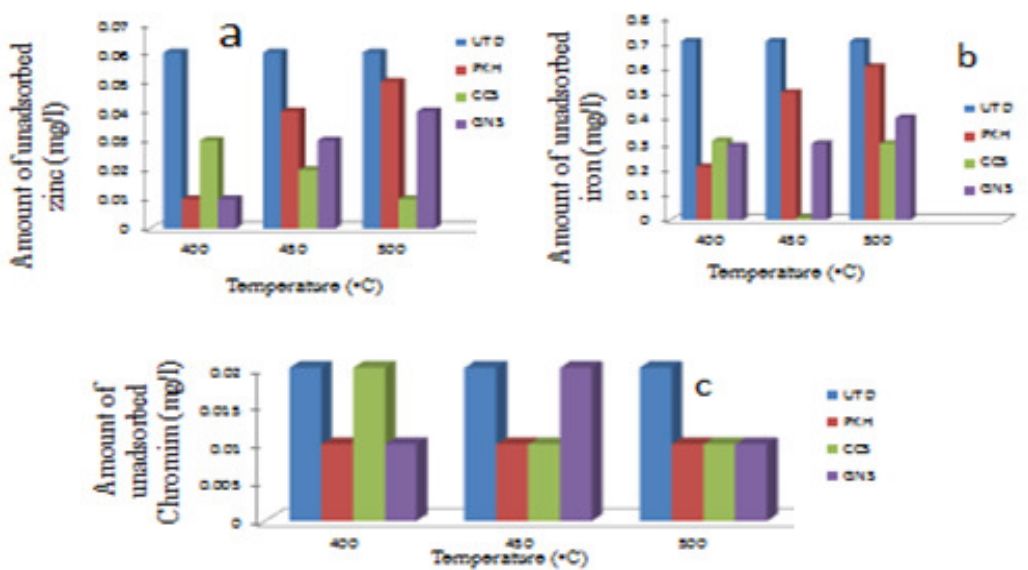

Fig 1. Amount of un-adsorbed (a) zinc (b) iron (c) chromium for $0.1 \mathrm{M} \mathrm{KOH}$ with palm kernel husk (PKH), coconut shell (CCS), groundnut shell (GNS) as adsorbent and untreated (UTD)

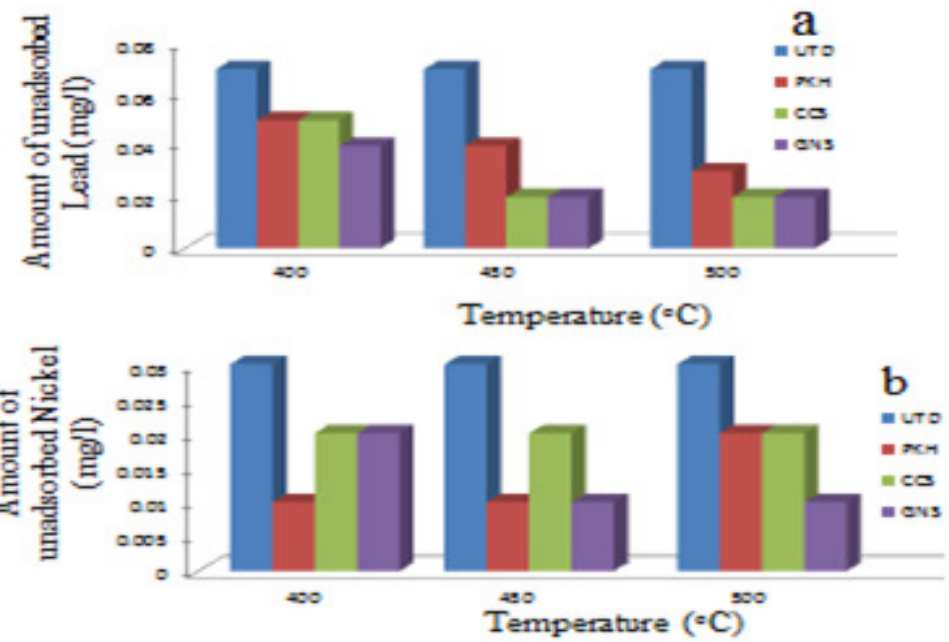

Fig 2: Amount of un-adsorbed (a) zinc (b) lead (c) nickel for 0.1 M KOH with palm kernel husk (PKH), coconut shell (CCS), groundnut shell (GNS) as adsorbent and untreated (UTD)

Figures 3 to 4 show the performance of the different adsorbents treated with $0.2 \mathrm{M} \mathrm{KOH}$ activated at temperatures of $400^{\circ} \mathrm{C}, 450^{\circ} \mathrm{C}$ and $500^{\circ} \mathrm{C}$. Figure $3($ a) specifically highlights the performance of the adsorbents at the different temperatures in the removal of Zinc metal. The result shows that as temperatures increases, increasing $\mathrm{KOH}$ from $0.1 \mathrm{M}$ to $0.2 \mathrm{M}$ did not translate to increase in the adsorption of Zinc by any of the adsorbents compared to the case of $0.1 \mathrm{M}$ which gave considerably lower un-adsorbed zinc concentration by the different adsorbents at different temperatures. This could be attributed to the fact that metal ions are more soluble at lower $\mathrm{pH}$ values and this increases their adsorption as observed by Olayinka et al., (2009). Removal of metal ions at higher $\mathrm{pH}$ values could be attributed to the formation of their hydroxides which results in precipitates, this is consistent with the observation of Lisa et al., (2004) and Xiao and Ju-Chang, (2009). Therefore, removal of metal ions at higher $\mathrm{pH}$ values is due to precipitation rather than adsorption (Kim et al., 2005). This suggests that $0.1 \mathrm{M}$ may be the optimum concentration of $\mathrm{KOH}$ for activation of these adsorbents for Zinc removal. This is due to the fact that the micropores are most developed in the internal void structure of activated carbon using 0.1M KOH. (Yang et al., 2017) Figure 3(b) shows the performance of the adsorbents in the removal of Iron. The result obtained using $0.2 \mathrm{M}$ of $\mathrm{KOH}$ at $400{ }^{\circ} \mathrm{C}$ gave un-adsorbed Iron concentration of $0.4 \mathrm{mg} / 1,0.3 \mathrm{mg} / 1$ and $0.1 \mathrm{mg} / \mathrm{l}$ for PKH, CCS and GNS respectively. Comparing these values with what was obtained at $450{ }^{\circ} \mathrm{C}$ and $500{ }^{\circ} \mathrm{C}$, it was observed that there was a gradual increase in the amount of unadsorbed Iron for all the adsorbents suggesting that $400{ }^{\circ} \mathrm{C}$ could be an optimum temperature for Iron removal using these adsorbents. Also, comparing the amount of un-adsorbed iron for $0.2 \mathrm{M}$ and $0.1 \mathrm{M} \mathrm{KOH}$, it was observed that adsorption of Iron using $0.1 \mathrm{M}$ 
$\mathrm{KOH}$ gave better result than $0.2 \mathrm{M} \mathrm{KOH}$. This suggests that $0.1 \mathrm{M}$ could be a better activation concentration of these adsorbents using $\mathrm{KOH}$. Higher concentration of activating agent $(0.2 \mathrm{M} \mathrm{KOH})$ leads to excessive activation which destroyed the internal structure of the activated carbon with part of the micropores turning into large pores resulting in a decrease in adsorption. Thus, the concentration of $\mathrm{KOH}$ solution has an influence on the preparation and adsorption ability of activated carbons. (Yang et al., 2017). From Figure 3(c), it was observed that the unadsorbed Chromium concentration was $0.1 \mathrm{mg} / \mathrm{l}, 0.2$ $\mathrm{mg} / \mathrm{l}$ and $0.1 \mathrm{mg} / \mathrm{l}$ using PKH, CCS and GNS at 400 ${ }^{\circ} \mathrm{C}$ respectively; $0.2 \mathrm{mg} / \mathrm{l}$ for all adsorbents at $450{ }^{\circ} \mathrm{C}$ and $0.2 \mathrm{mg} / 1,0.1 \mathrm{mg} / \mathrm{l}$ and $0.2 \mathrm{mg} / \mathrm{l}$ for PKH, CCS and GNS respectively. This suggests that PKH and GNS will perform better at $400{ }^{\circ} \mathrm{C}$ while CCS will do well at $500{ }^{\circ} \mathrm{C}$ when activated with $0.2 \mathrm{M} \mathrm{KOH}$. Comparing the performance of these adsorbents in Chromium removal using $0.2 \mathrm{M} \mathrm{KOH}$ to that of $0.1 \mathrm{M} \mathrm{KOH}$, it
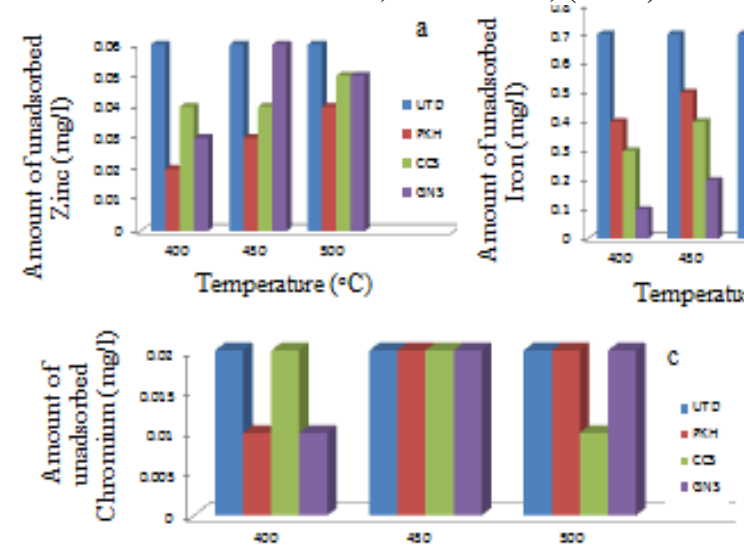

Temperature $\left({ }^{\circ} \mathrm{C}\right)$ et al., (2014). was observed that for temperatures $400{ }^{\circ} \mathrm{C}, 450{ }^{\circ} \mathrm{C}$ and $500{ }^{\circ} \mathrm{C}$ when $0.2 \mathrm{M} \mathrm{KOH}$ was used, the lowest unadsorbed Chromium concentration was $0.1 \mathrm{mg} / \mathrm{l}$ however, for $0.1 \mathrm{M} \mathrm{KOH}, 0.01 \mathrm{mg} / \mathrm{l}$ was recorded. This suggests that $\mathrm{KOH}$ activation concentration of $0.1 \mathrm{M}$ will work better for these adsorbents than $0.2 \mathrm{M}$ for similar reasons mentioned above. Figure 4(a) shows the un-adsorbed concentration of Lead. It was observed that the un-adsorbed Lead concentration for $0.2 \mathrm{M} \mathrm{KOH}$ was $0.03 \mathrm{mg} / \mathrm{l}, 0.04 \mathrm{mg} / \mathrm{l}$ and $0.03 \mathrm{mg} / \mathrm{l}$ at $400{ }^{\circ} \mathrm{C} ; 0.050 \mathrm{mg} / \mathrm{l}, 0.050 \mathrm{mg} / \mathrm{l}$ and $0.06 \mathrm{mg} / \mathrm{l}$ at 450 ${ }^{\circ} \mathrm{C}$ and $0.03 \mathrm{mg} / \mathrm{l}, 0.06 \mathrm{mg} / \mathrm{l}, 0.06 \mathrm{mg} / \mathrm{l}$ at $500{ }^{\circ} \mathrm{C}$ for PKH, CCS and GNS respectively. However, when 0.1 $\mathrm{M} \mathrm{KOH}$ was used, the performance at $450{ }^{\circ} \mathrm{C}$ and 500 ${ }^{\circ} \mathrm{C}$ seems better for all adsorbents giving a minimal unadsorbed concentration of $0.03 \mathrm{mg} / \mathrm{l}(\mathrm{PKH})$ and 0.02 $\mathrm{mg} / \mathrm{l}$ for CCS and GNS. Adsorbents prepared by $\mathrm{KOH}$ activation exhibit great advantage in Lead ion removal from aqueous solutions as also observed by Chengwen

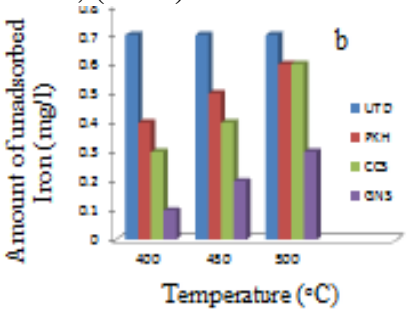

Fig 3: Amount of un-adsorbed (a) zinc (b) iron (c) chromium for $0.2 \mathrm{M} \mathrm{KOH}$ with palm kernel husk (PKH), coconut shell (CCS), groundnut shell (GNS) as adsorbent and untreated (UTD)
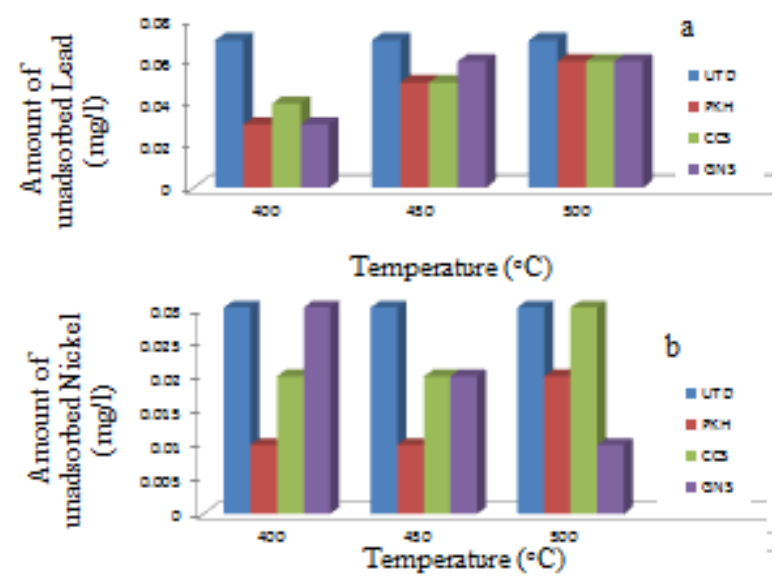

Fig 4: Amount of un-adsorbed (a) lead (b) nickel 0.2 M KOH with palm kernel husk (PKH), coconut shell (CCS), groundnut shell (GNS) as adsorbent and untreated (UTD) 
Figure 4(b) then shows the un-adsorbed Nickel when the adsorbents were used at the operating temperatures. It was observed that $\mathrm{PKH}$ performed better at $400{ }^{\circ} \mathrm{C}$ and $450{ }^{\circ} \mathrm{C}$ while GNS was at $500{ }^{\circ} \mathrm{C}$ with $0.01 \mathrm{mg} / \mathrm{l}$ un-adsorbed Nickel concentration. Interestingly, the trend observed in this case with 0.2 $\mathrm{M} \mathrm{KOH}$ seems to be very similar to that for $0.1 \mathrm{M}$ $\mathrm{KOH}$. This suggests that for Nickel adsorption using these adsorbents, the concentration of the activating agent $(0.1 \mathrm{M}$ and $0.2 \mathrm{M})$ may not be of serious consequence. The purpose of $\mathrm{KOH}$ activation is to activate the mesopores and micropores of the activated carbon. (Yang et al., 2017) However, at optimum concentration of activating agent, the adsorption capability of the adsorbents remains unchanged which implies that the optimum concentration for activating agent has been achieved.

Specifically, Figure 5(a) shows the adsorption profile for Zinc using $0.1 \mathrm{M} \mathrm{ZnCl}_{2}$. At $400{ }^{\circ} \mathrm{C}$, it was observed that PKH, CCS and GNS recorded un-adsorbed Zinc concentration of $0.01,0.04$ and $0.01 \mathrm{mg} / 1$ respectively. Comparing this result with what was obtained when $\mathrm{KOH}$ was used, it was observed that the performance of the adsorbents where the same except for CCS where 0.03 was recorded for $\mathrm{KOH}$. However, at 450 ${ }^{\circ} \mathrm{C}$ which seems to be the optimum temperature for
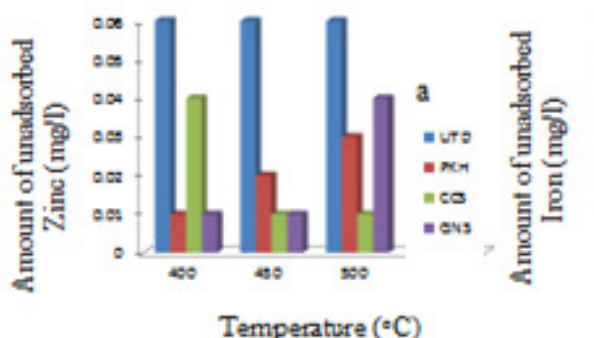

$\mathrm{ZnCl}_{2}$ activation, the result seems very well better than when $\mathrm{KOH}$ was used and at $500{ }^{\circ} \mathrm{C}$, there was not much observable difference in the adsorbent performance for both activating agents. This suggest that for Zinc adsorption, activating the adsorbent using Zinc chloride could be a better option as this will ensure cleaner and safer water. Figure 5(b) describes the removal of Iron using the adsorbents on activation with $0.1 \mathrm{M} \mathrm{ZnCl}_{2}$ at $400{ }^{\circ} \mathrm{C}$ to $500{ }^{\circ} \mathrm{C}$. At $500{ }^{\circ} \mathrm{C}$, all adsorbents gave the same amount of un-adsorbed Iron while the result showed the least set of un-adsorbed Iron and the highest at $450{ }^{\circ} \mathrm{C}$. This shows that removal of Iron by the selected adsorbents could be temperature dependent. In Figure 5(c), the removal of Chromium was described. It was observed that for all adsorbents and all temperatures, the un-adsorbed Chromium concentration was $0.01 \mathrm{mg} / \mathrm{l}$ except for 400 ${ }^{\circ} \mathrm{C}$ where CCS and GNS showed a poor performance and left the Chromium concentration still at $0.02 \mathrm{mg} / \mathrm{l}$. This suggest that while Chromium adsorption could be temperature sensitive, it is more sensitive for CCS and GNS and that PKH could be better for Chromium adsorption comparing the performances of the three adsorbents. Owlad et al., (2010) reported a $12.6 \mathrm{mg} / \mathrm{g}$ adsorption capacity for $\mathrm{Cr}$ (VI) ion in impregnated palm shell activated carbon with polyethylenemine..

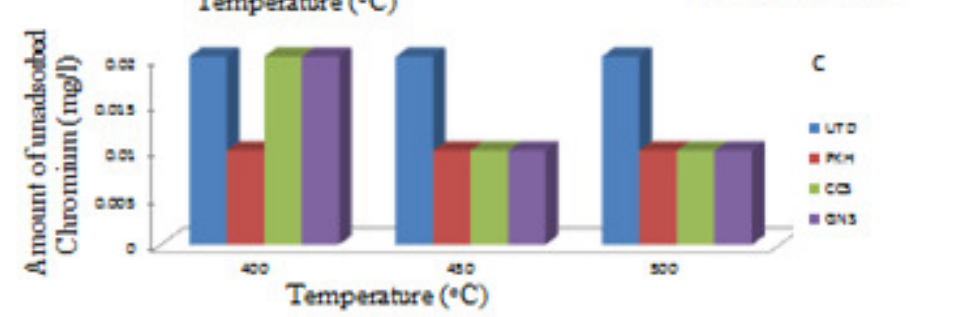

Fig 5: Amount of un-adsorbed (a) zinc (b) iron (c) chromium 0.2 M KOH with palm kernel husk (PKH), coconut shell (CCS), groundnut shell (GNS) as adsorbent and untreated (UTD)

This confirms that PKH is a good adsorbent for Chromium ion removal from waste-water. The performance of the adsorbents in Lead adsorption is presented in Figure 6(a). It is evident that the adsorbents performed well at $400{ }^{\circ} \mathrm{C}$ and $450^{\circ} \mathrm{C}$ giving un-adsorbed Lead concentration of $0.01 \mathrm{mg} / \mathrm{l}$ except PKH that gave $0.02 \mathrm{mg} / 1$ at $450{ }^{\circ} \mathrm{C}$. However, at 500 ${ }^{\circ} \mathrm{C}$, it can be observed that the Lead concentration barely reduced to $0.03 \mathrm{mg} / \mathrm{l}, 0.04 \mathrm{mg} / \mathrm{l}$ and $0.04 \mathrm{mg} / \mathrm{l}$ for PKH, CCS and GNS respectively. This suggests that at $400{ }^{\circ} \mathrm{C}$ and $450{ }^{\circ} \mathrm{C}$, the adsorbents will perform optimally and $400^{\circ} \mathrm{C}$ could be the optimal temperature for all three adsorbent since it gave the lowest unadsorbed Lead concentration. Figure 6(b) examines the adsorption of Nickel for $0.1 \mathrm{M} \mathrm{ZnCl} 2$. It was observed that the performance of PKH and CCS improved as temperature increased while for GNS the performance was optimum at $400{ }^{\circ} \mathrm{C}$. In all, $\mathrm{PKH}$ showed a better performance in all three temperatures Finally, Figures 7 to 8 show the effect of increase in 
concentration of $\mathrm{ZnCl}_{2}$ from $0.1 \mathrm{M}$ to $0.2 \mathrm{M}$ on the adsorption capacities of the different adsorbents. Figure 7(a) shows the performance of the adsorbents on Zinc removal. It was observed that CCS performed better making it the preferred adsorbent for Zinc adsorption. However, comparing these performances to that of $0.1 \mathrm{M} \mathrm{ZnCl}_{2}$ above, it was observed that the case with $0.1 \mathrm{M} \mathrm{ZnCl}_{2}$ seems to have been better since concentrations as low as $0.1 \mathrm{mg} / \mathrm{l}$ were recorded for all adsorbents at different temperatures.

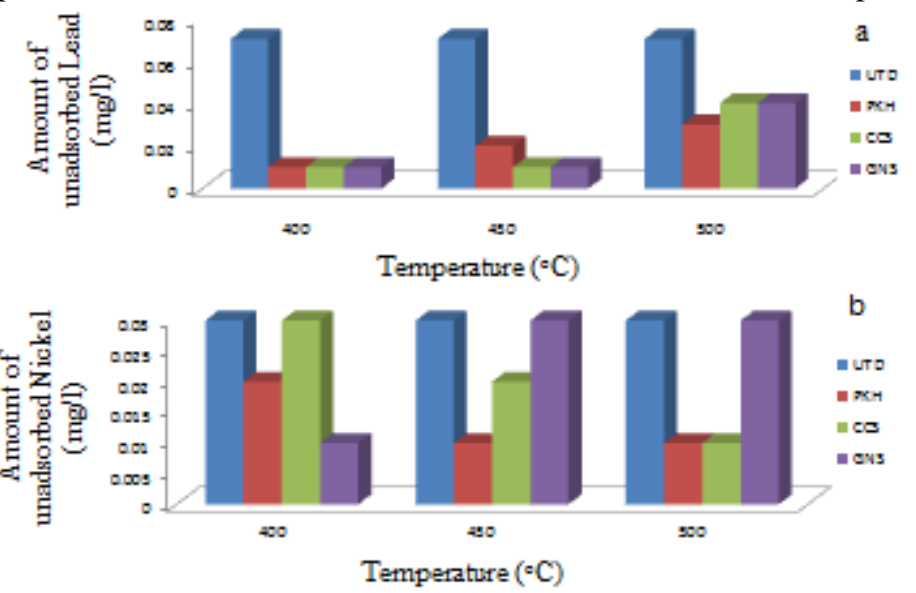

Fig 6: Concentration of un-adsorbed (a) lead (b) nickel metal using palm kernel husk (PKH), coconut shell (CCS), groundnut shell (GNS) activated with $0.1 \mathrm{M} \mathrm{Zn} \mathrm{Cl}_{2}$ as adsorbent and untreated (UTD) waste-water

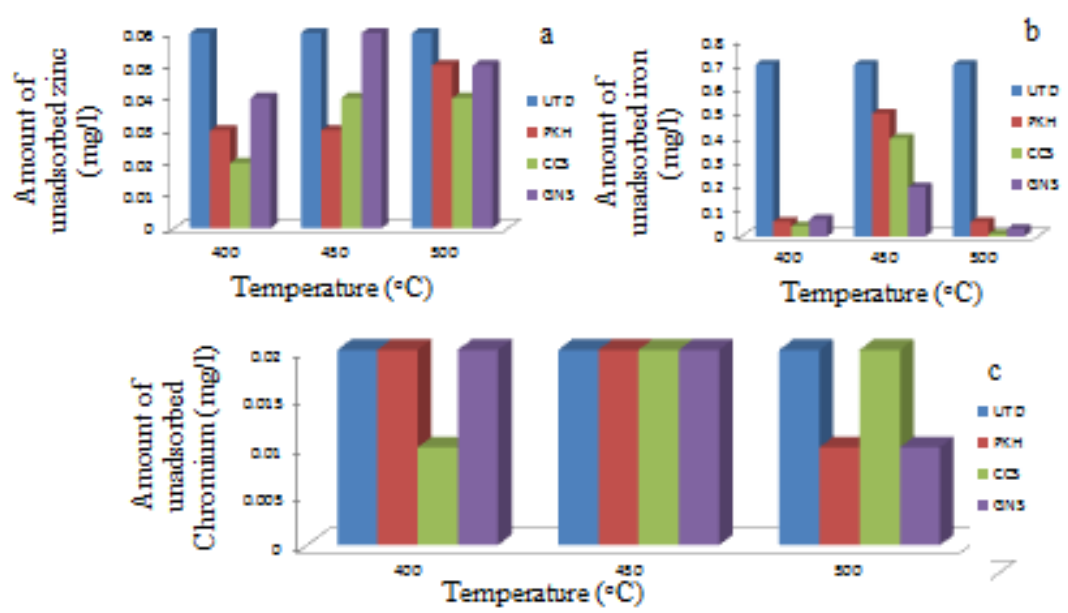

Fig 7. Concentration of un-adsorbed (a) $\mathrm{Zn}$ (b) Fe (c) Cr metal using PKH, CCS, and GNS activated with $0.2 \mathrm{M} \mathrm{ZnC}_{12}$ and untreated (UTD) wastewater

Figure 7(b) shows the performance of the adsorbents in the removal of Iron. PKH did not show good Iron removal capacity with activation using $0.2 \mathrm{M} \mathrm{ZnCl}_{2}$ as compared to the degree of Iron recovery recorded in the case of $0.1 \mathrm{M} \mathrm{ZnCl}_{2}$ across all temperature used for this study. Similar observation was noted with CCS at lower temperatures. However, it gave a relatively good result at $500{ }^{\circ} \mathrm{C}$ suggesting that the performance of CCS is highly temperature dependent. GNS on the other hand gave an optimum performance at $450{ }^{\circ} \mathrm{C}$ with $0.2 \mathrm{mg} / \mathrm{l}$ of un-adsorbed Iron. This value is the same as the optimum value recorded for $0.1 \mathrm{M}$ but at a different temperature. This suggests that the performance is highly temperature dependent. Figure 7(c) describes the performance of the adsorbents in the removal of Chromium. Like the case of $0.1 \mathrm{M} \mathrm{ZnCl}_{2}$, all three adsorbents showed capacity to reduce Chromium but to $50 \%$ at any stage. However, this capacity is also temperature dependent as can be seen from the figure. Figure 8(a) describes the capacity of the adsorbents to remove Lead. The results suggest that the adsorbents activated with $0.2 \mathrm{M} \mathrm{ZnCl}_{2}$ have low capacity to remove lead compared to what was recorded for $0.1 \mathrm{M}$ irrespective of the operating temperature. Figure 8(b) describes the removal of Nickel on activation with $0.2 \mathrm{M} \mathrm{ZnCl}_{2}$. The result shows that the performance is not different from what was recorded for $0.1 \mathrm{M} \mathrm{ZnCl}_{2}$ but the temperatures are quite different. From Figure 7 to 8, it was observed that the activation temperature seemed to have played an 
important role in the heavy metal removal. This is because temperature has been identified as an important factor which affects the sorption capacity of adsorbents. XiaBiao et al, (2013) observed that increasing the calcination temperature leads to increasing porosity and available surface area which enhance the adsorption capacity of the adsorbents. It is therefore expected that when the activation temperature increases, the heavy metal removal rate for different adsorbents will increase
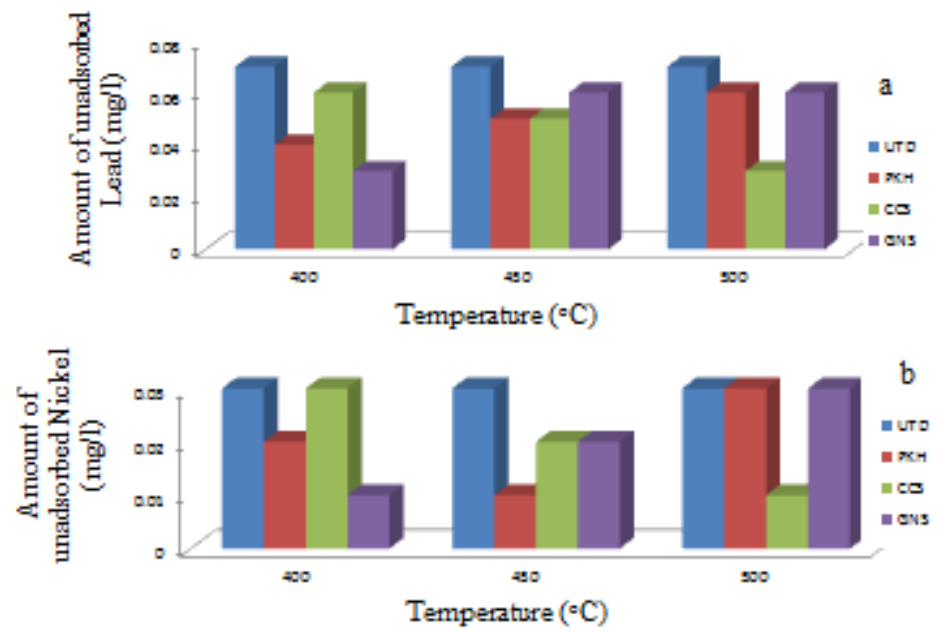

Fig 8. Concentration of un-adsorbed (a) $\mathrm{Pb}$ (b) Ni metal using $\mathrm{PKH}, \mathrm{CCS}$, and GNS activated with $0.2 \mathrm{M} \mathrm{ZnC}_{\mathrm{l} 2}$ and untreated (UTD) wastewater

In general, CCS seems to have better adsorption capacity compared to PKH and GNS for the different temperatures and concentrations of the two activating agents. Similar conclusion was made in a recent study by Boadu et al., (2018), that CCS have good physicochemical properties for adsorption and is a better advantage to be used as an adsorbent for heavy metals compared to GNS and PKH due to its good pore diameter of $2.840 \mathrm{~nm}$ and high BET (BrunauerEmmett-Teller) surface area of $1177.520 \mathrm{~m}^{2} / \mathrm{g}$ an indication of the presence of many adsorption sites.

Conclusions: This work has shown that PKH, CCS and GNS could be used as alternative to available commercial adsorbents for cement waste water. It has also affirmed that the combination of physical and chemical treatment of these adsorbents could enhance their adsorption capabilities due to their resultant high surface area and increased depth of pore spaces. Within the scope of the experimental investigation, the adsorption capacities showed sensitivity to temperature, with an inverse relationship for $\mathrm{PKH}$ and CCS and direct relationship for GNS.

\section{REFERENCES}

Abdulrasaq, OO; Basiru O.G (2010). Removal of copper (II), iron (III) and lead (II) ions from mono-component simulated waste effluent by adsorption on coconut husk. Afri. J. of Environ. Sci. and Technol. 4(6): 382-387
Agbozu, IE; Emoruwa FO (2014). Batch adsorption of heavy metals $(\mathrm{Cu}, \mathrm{Pb}, \mathrm{Fe}, \mathrm{Cr}$ and $\mathrm{Cd})$ from aqueous solutions using coconut husk. Afri. J. of Environ. Sci. and Technol. 8(4): 239-246

Aiphing, L; Ahmad ZA (2014). A review on economically adsorbents on heavy metals removal in water and wastewater. Rev. in Enviro.. Sci. and Bio/Technol. 13(2): 163-181

Al-Degs, SY; El-Barghouthi IM; El-Sheikh, HA; Walker, MG (2007). Effect of solution $\mathrm{pH}$, ionic Strength, and temperature on adsorption behavior of reactive dyes on activated carbon, Dyes and Pigments. DOI:1016/j.dyepig.2007.03.001

Bernard, E; Jimoh, A; Odigwe, JO (2013). Heavy Metals removal from Industrial Wastewater by Activated Carbon Prepared from Coconut Shell. Res. J. of Chemi. Sci. 3(8): .3-9

Bing, FQ (2011). Removal of Heavy Metal Ion from Waste Water. J. of Environ. Manag. 407-418

Boadu, KO; Joel, OF; Essumang, DK; Evbuomwan, BO (2018). comparative studies of the Physicochemical Properties and Heavy Metals adsorption Capacity of Chemical Activated Carbon from Palm Kernel, Coconut and Groundnut shells. J. of Appl. Sci. and Environ. Manag.. 22(11): 1833-1839 
Chengwen, S; Shuaihua, W; Murong, C; Ping, T; Mihua, S; Guangrui, G (2014). Adsorption Studies of Coconut Shell Carbons Prepared by $\mathrm{KOH}$ Activation for Removal of Lead (II) from Aqueous Solutions. Sust., 6: 86-98;

Elijah, T I; Ogechi SE; Opete, I (2009). Removal of Chromium and Lead from drill cuttings using activated palm kernel shell and husk. Afri. J. of Environ. Sci. and Technol. 3(7): 171-179

Eruola, AO; Ogunyemi, IO (2014). Evaluation of the Adsorption Capacity of the Coconut Shell and Palm-kernel Shell Adsorbents Powder for the Sorption of Cadmium (II) ions from Aqueous Solution. IOSR J. of Environ. Sci., Toxicol. and Food Technol. 8( 6): 55-63

European Cement Association (1996). Guidelines and Standards for Environ. Disch. of Cement Waste Water. 6: 54

Francis, KM; Francis, OA; Francis, ON (2014). Analyses of Physical And Chemical Parameters In Surface Waters Nearby A Cement Factory In North Central, Nigeria, J. of Environ. Prot., 5: 826-834

Gregg, S J; Sing, KW (2002). Adsorption, Surface Area and Porosity, London: Acad. press.

Gonzalo, MA; Bermudez, MM; Rodrigo, I; Rita, P; María, LP (2010) Heavy metal pollution in topsoils near a cement plant: The role of organic matter and distance to the source to predict total and $\mathrm{HCl}$-extracted heavy metal concentrations. Chemosph. 78: 375-381

Huang, CP; Merchant, AL (1991). Piston Competition in $\mathrm{Co}(\mathrm{ii}) \mathrm{r}$ Adsorption in Frugal Mycella. Int. Water Res. J. 1:1365-1375.

McCabe, JCSPH (2005). Unit operation of Chemical Engineering. 7th ed. New York: McGraw-Hill.

Nasim, AK; Shaliza, I; Piarapakaran, S (2004). Elimination of Heavy Metals from Wastewater Using Agricultural Waste as Adsorbents. Malays. J. of Sci. 23(1): 188-196

Nur, AF; Ahmmed, SI; Kamariah, NI (2014). Removal of Heavy Metals from Simulated Wastewater Using Physically and Chemically Modified Palm Shell Activated Carbon. J. of Appli. Sci. 14: 1294 1298
Omar, E; Abdel, S; Neama, A; Reiad, M; Elshafei, M (2011). A study of the removal characteristics of heavy metals from wastewater by low-cost adsorbents. J. of Adv. Res. 2: 297-303

Owlad, M; Aroua, MK; Daud, W (2010). Hexavalent chromium adsorption in impregnated palm shell activated carbon with polyethylenemine. Biores. Technol. 101(14): 5098-5103

Pandey, G; Madhin, S (2014). Heavy metals toxicity in Animals and Fishes. Res. J.Animal, Vert. and Fishery Sci. 2(2): 17-23

Radia, L; Oumessaad, B; Adh'Ya, EH; Andre, D (2018). Adsorption of hexavalent chromium by activated carbon obtained from a waste lignocellulosic material (ziziphus jujuba cores): Kinetic, equilibrium, and thermodynamic study. Adsorpt. Sci. and Technol. 36(2-4): 1066-1099

Skinnes, JH; Basin, NJ (1988). The Environmental Protection Agency's Hazardous Waste Management Research and Development Program, s.l.: APCA Int.

Wan, N; Hanafiah, MA (2008). Removal of Heavy Metal Ions from Waste Water by Chemically Modified plant Wastes as Adsorbent: A Rev.. Biores. Technol. 99: 3935-3948

William JS; Mwegoha, M; Lema, WJ (2016). Effectiveness of Activated Groundnut Shells to Remove Chromium from Tannery Wastewater. Inter. J. of Environ. Monit. and Prot. 3(4): 36-42

XiaBiao, B; ZhenNeng, L; LingBao, W (2013). Preparation of Composite Adsorbent with High Performance of Heat and Mass Transfer. Chinese Sci. Bullet. 58(30): 3709 - 3714

Yang, HM; Zhang, DH; Chen, Y; Ran, MJ; Gu, JC (2017). Study on the application of $\mathrm{KOH}$ to produce activated carbon to realize the utilization of distiller's grains. $3^{\text {rd }}$ International Conference on Advances in Energy, Environment and Chemical Engineering, IOP Conf. Ser.: Earth and Environ. Sci. 69 